\title{
COMENTARIO A LA JURISPRUDENCIA CONSTITUCIONAL DE LA CORTE SUPREMA CHILENA DURANTE EL AÑO 2001
}

\author{
Pablo Ruiz-Tagle Vial*
}

A. Introducción; B. Acción de Reclamación de Nacionalidad; C. Acción de Protección: 1. Acciones de protección dirigidas contra personas privadas; 2. Acciones de protección contra personas públicas de gobierno y administración; 3. Acciones de protección contra personas que ejercen potestades jurisdiccionales; $D$. Acción de Amparo Económico; E. Acción de Amparo; F. Acción de Inaplicabilidad; G. Casación en el Fondo; H. Conclusiones.

\section{A. Introducción}

Desde hace bastante tiempo se ha planteado la necesidad de realizar estudios críticos sobre las sentencias emanadas de los tribunales de justicia chilenos que pudiesen reunir observaciones al trabajo judicial durante uno o más ciclos o periodos y en materias determinadas. ${ }^{1}$ Este propósito tiene su fundamento en la práctica de recopilar las decisiones judiciales que puede encontrarse en el derecho comparado. A este respecto René David señala: "Estas recopilaciones oficiales (de sentencias) pueden servirnos para formular una distinción que raras veces se está dispuesto a reconocer, entre sentencias que merecen crear jurisprudencia y otras que mejor sería olvidar."2

La práctica de comentar las sentencias ha sido recomendada entre nosotros por Andrés Bello, quien ha vinculado la idea de fundar las sentencias, someterlas a la publicidad y su crítica, como un rasgo característico de las instituciones republicanas en los países más civilizados. Andrés Bello ha dicho que

Véase, si no, las colecciones de causas y juzgamientos que se publican en Inglaterra, Francia y los Estados Unidos; compárense las profundas y lúcidas discusiones legales recopiladas en ellas con las glosas y comentarios de casi todos nuestros expositores, en que lo rancio de las formas, lo licencioso de las interpretaciones, las argucias casuísticas, el interminable cúmulo de citas en que se hunde a cada paso el texto, como un río tortuoso que se pierde entre arenales para reaparecer a algunas

\footnotetext{
* Abogado (Universidad de Chile), Doctor en Derecho (Universidad de Yale), profesor de Derecho Constitucional e Introducción al Derecho en la Facultad de Derecho de la Universidad de Chile. Una versión de este trabajo fue revisada por el profesor Cristián Banfi y por el ayudante Miguel Gonzalez Lemus; también ayudaron en esta revisión los alumnos Diego Gil y Juan Pablo Bulnes. Algunas ideas del presente texto forman parte de la investigación mas extensa sobre derechos fundamentales que cuenta con el apoyo de FONDECYT y que lleva el No.1020348.

1 Ver en Evolución De La Cultura Jurídica Chilena (Agustín Squella ed., Santiago: Corporación de Promoción Universitaria, 1994), sección de Ruiz-Tagle, Pablo “Comunicación sobre el trabajo de Carlos Peña," p 185: podrían hacerse seguimientos de causas para identificar tendencias constitucionales mayoritarias y discrepancias entre salas o jueces individuales en recursos de protección en ciertas materias específicas como propiedad, igualdad, libertad de expresión, conflictos de competencia, etc. También seguir tendencias constitucionales en el Tribunal Constitucional. Estudiar como respetan los derechos constitucionales el gobierno y los organismos policiales en las gestiones de indagación, detención y prisión. Estudiar normas aceptadas por el derecho chileno que impliquen discriminación contra la mujer, etc.

2 David, R., Los Grandes Sistemas Jurídicos Contemporáneos p 103 (Madrid: Aguilar, 1969).
} 
Ruiz-Tagle - Jurisprudencia Corte Suprema 2001: Derecho Constitucional

leguas de distancia, en una palabra, la falta de filosofía, y a veces hasta de sentido común, hace desabrida y fatigosa la lectura, empaña aún la buena doctrina y desacredita las ciencias legales. ${ }^{3}$

Después de constatar la verdad de los juicios tan severos emitidos por alguien del ascendiente de Andrés Bello, lo que más llama la atención es que en nuestro país no se haya asentado una crítica jurisprudencial mas institucionalizada. Desde luego, la Revista de Derecho y Jurisprudencia con su selección de sentencias y el desarrollo de su doctrina representa un esfuerzo aislado y parcelado, pero el punto de vista que se ha adoptado en la crítica formulada desde esta prestigiosa publicación, resulta todavía punto insuficiente. Por eso, la forma del comentario anual se presta para hacer un análisis más comprensivo y permite aunar esfuerzos de varios estudiosos de diversas disciplinas jurídicas y sociales que arriesguen una opinión sobre el progreso o el retroceso de las causas judiciales en Chile.

Un intento reciente de juzgar de manera global las decisiones judiciales del año recién pasado se concretó en un comentario periodístico que hizo el profesor de la Pontificia Universidad Católica Arturo Fermandois en el diario El Mercurio. El profesor Fermandois propuso entonces revisar la calidad de las sentencias judiciales pronunciadas el año $2001,{ }^{4}$ de acuerdo a lo que denominó un 'criterio de calidad,' según el cual:

una sentencia de calidad es la que ampara con decisión un derecho fundamental vulnerado, respetando la identidad de las instituciones procesales. Un fallo modelo es aquel que es capaz de sobreponerse al tamaño, prestigio o influencia pública de una de las partes para socorrer con independencia y velocidad al más débil, si los derechos que invoca se encuentran efectivamente comprometidos. ${ }^{5}$

Los criterios de Fermandois, aunque respetables, desgraciadamente parecen incompletos. Por una parte, en lo que respecta al derecho constitucional creo necesario considerar también la manera en que la jurisprudencia de calidad contribuye a la consolidación y avance de la democracia. Democracia por cierto se entiende como el gobierno de la mayoría sometido al derecho, gobierno que respeta también la participación y los derechos de las minorías. En este sentido, comentar el trabajo judicial a partir del criterio de la democracia supone analizar la argumentación constitucional en el ámbito judicial estudiando en qué medida se utilizan o se prescinde de criterios de ponderación y de razonabilidad ante los casos de colisión de derechos fundamentales. Implica, además, observar el tratamiento de estas garantías y el ámbito en que son protegidas a través de la

\footnotetext{
3 Bello, A., "Necesidad de Fundar las Sentencias," El Araucano 1834 y 1839, en Escritos Políticos (Valparaíso: Edeval, 1979).

4 Arturo Fermandois, "Los Mejores Fallos de 2001," diario El Mercurio, 19 de enero de 2002, p A2.

5 Idem supra nota anterior. Hay un error en los fallos mencionados por el profesor Fermandois porque asumiendo un entusiasmo anti-estatal un tanto irreflexivo llegó a inventar y felicitar en su nota periodística el resultado de un caso que en verdad nunca existió. Este es el caso que Fermandois denominó Ruiz con Fisco y que supuestamente según él, resolvió que una persona debía ser indemnizada por el Estado por ser un paciente al que se le había diagnosticado erróneamente con SIDA. En verdad, como aclaró el abogado Jose Bernales en una carta de fecha 4 de febrero de 2002 al mismo diario El Mercurio el pleito al que se refería en forma equivocada el señor Fermandois: “está caratulado 'Ruiz con Laboratorio Biológico S.A. y otros' y el único condenado a pagar la indemnización es dicho laboratorio. . . . El fisco, uno de los demandados fue declarado exento de toda responsabilidad." La carta del señor Bernales ahorra muchos comentarios. Se advierte eso sí, que este caso no es comentado en esta sección constitucional porque al parecer se trata de un juicio indemnizatorio civil que se resolvió por la vía de reconocer el daño moral causado por el laboratorio a la víctima.
} 
REJ - Revista de Estudios de la Justicia - No 3 - Año 2003

función jurisdiccional. El criterio de promover la democracia no está presente entre las ideas de Fermandois para juzgar si una decisión judicial constitucional es positiva o no.

Además, la posibilidad de hacer una crítica al trabajo judicial tiene siempre sus limitaciones porque incluye acciones muy diversas. Por ejemplo en el presente trabajo se han incluido sentencias de protección, de inaplicabilidad, reclamos de nacionalidad, y de amparo económico, pero no se han incluido los fallos del Tribunal Constitucional. Estas otras sentencias tienen relación con el tipo de análisis comprensivo que se pretende proponer en estas líneas.

Explicadas entonces las limitaciones anteriores, enumeramos a continuación el universo total de decisiones judiciales que hemos tenido a la vista para realizar este estudio crítico. Si se escapa alguna sentencia relevante, se habría detectado un error en el presente trabajo que por supuesto tendrá que ser subsanado en sus próximas ediciones. El listado de casos con sus roles y fechas respectivos es el siguiente:

1. Gaete Quezada Miguel Angel y el Instituto Normalización Previsional, rol 3494-99, 19 de enero de 2001, Libro Civil, No 9-10, inaplicabilidad;

2. Pardo con Burger, rol 2232-00, 25 de enero de 2001, Libro Civil, No 7-10, casación forma y fondo;

3. De la Fuente Badilla Juan Carol, rol 4657-1999, 26 de enero de 2001, Libro Civil, No 6-10, reclamo nacionalidad;

4. Sáez Luco Sonia con Instituto Normalización Previsional, rol 3495-99, 29 de enero de 2001, Libro Laboral, No 9-10, inaplicabilidad;

5. Sociedad Importador Promather Ltda. con Inspección Provincial del Trabajo de Concepción, rol 4383-2000, 14 de marzo de 2001, Libro Protecciones, № 2-3, protección;

6. Cáceres Blandida del Carmen, rol 3612-96, 16 de marzo de 2001, Libro Civil, No 3-6, inaplicabilidad;

7. Lander de Tellitsu Sasía con Fisco, rol 2218-00, 18 de abril de 2001, Libro Civil, No 5-7, casación de forma y fondo;

8. María Tecay Paillan con Sr. Juez del Tercer juzgado de Letras de Magallanes, rol 16932001, 4 de junio de 2001, Libro Criminal, No 1-8, amparo;

9. Chernilo Muller Ely y otros con I. Municipalidad de Rencay Contraloría General de la República, rol 1921-2001, 12 de junio de 2001, Libro Protecciones, No 1-4, protección;

10. Electricidad Gobantes S.A. con Director del S.I.I., rol 2036-2001, 14 de junio de 2001, Libro Civil, $\mathrm{N}^{\mathrm{o}} 1-4$, protección;

11. Sáez con Fisco de Chile, rol 862-00, 21 de junio de 2001, Libro Civil, No 7-10, inaplicabilidad;

12. Sernap con Fuentes y otro, rol 3946-99, 6 de julio de 2001, Libro Civil, $N^{\circ} 1-13$, inaplicabilidad;

13. Manganesos Atacama S.A. con Servicio de Salud Coquimbo, rol 2274-01, 10 de julio de 2001, Libro Protecciones, $\mathrm{N}^{\mathrm{o}} 1-5$, protección;

14. Alimentos Marinos S.A "Alimar" con Subsecretaría de Pesca, rol 2421-2001, 17 de julio de 2001, Libro Protecciones, No 3-5, amparo económico;

15. Alejandro Gordillo Gordillo con Sr. Juez. del Cuarto Juzgado Civil de San Miguel, rol 21902001, 17 de julio de 2001, Libro Protecciones, N 3-5, protección;

16. Garrido Tuleda María y otros, rol 2838-2000, 3 de agosto de 2001, Libro Civil, No 1 7, inaplicabilidad;

17. Philippi Izquierdo, Sara, Nena, González, y otros con Laboratorio S.P., rol 2186-2001, 30 
Ruiz-Tagle - Jurisprudencia Corte Suprema 2001: Derecho Constitucional

de agosto de 2001, Libro Protecciones, No 4-4, protección;

18. Sociedad Comercial Rojas Hnos. O y D Limitada con Director Regional de Vialidad VI Región, rol 3226-01, 2 de octubre de 2001, Libro Protecciones, N N $^{\circ}$-4, amparo económico;

19. Flores Carvajal Graciela con Director Nacional del Instituto de Desarrollo Agropecuario y Contraloría General de la República, rol 3401-01, 4 de octubre de 2001, Libro Protecciones, $\mathrm{N}^{\mathrm{o}} 1-4$, protección;

20. Toledo Fuentes Oscar German con Director Nacional del Instituto Desarrollo Agropecuario, rol 2884-01, 4 de octubre de 2001, Libro Protecciones, N 1-4, protección;

21. Candia Henríquez. José Alcides con Director Nacional de INDAP, rol 3583-01, 4 de octubre de 2001, Libro Protecciones, $\mathrm{N}^{\mathrm{o}} 1-4$, protección;

22. Cayuman Henriquez. Luis y otros con Aylwin Azócar Arturo, Contralor General de la República, rol 3580-01, 4 de octubre de 2001, Libro Protecciones, N ${ }^{\circ}$ 1-4, protección;

23. Jorge Oschsenius Vargas con Serv. Salud Metropolitano Occidente, Rol 4865-00, 24 de octubre de 2001, Libro Civil, No 8-12, inaplicabilidad;

24. Sociedad Constructora Santa María del Campo Ltda. con Director de Serviu de la Región de Coquimbo, rol 3796-01, 29 de octubre de 2001, Libro Protecciones, N ${ }^{\circ} 4-4$, amparo económico;

25. Empresa Eléctrica Guacolda S.A. con Ministro de Economía, Fomento y Reconstrucción, rol 3797-01, 29 de octubre de 2001, Libro Protecciones, No 4-4, amparo económico;

26. Racimec Internacional con Tesorería Regional Metropolitano Santiago Oriente, rol 4262-01, 4 de diciembre de 2001, Libro Protecciones, No 1-3, protección;

27. Racimec Internacional con Tesorería Regional Metropolitano Santiago Oriente, rol 3951-01, 4 de diciembre de 2001, Libro Protecciones, No 1-3, protección.

Con el objeto de ordenar nuestras observaciones críticas se agrupan los casos conforme al tipo de acción constitucional que se ha ejercido y se comenta cada una de ellas en sus principales aspectos. Luego se intenta una conclusión más general sobre el periodo 2001 que se desprende de los resultados parciales y las ideas más generales que es posible extraer acerca de la jurisprudencia.

\section{B. Acción de Reclamación de Nacionalidad}

De todos los casos que comprende este trabajo, uno solo de ellos está referido a una acción de reclamación de pérdida al derecho de nacionalidad según dispone el artículo 12 de nuestra Constitución Política. Este se refiere a un chileno que residía en Argentina y que adquirió tal nacionalidad para continuar sus estudios de doctorado con una beca y que denominaremos caso De la Fuente. ${ }^{6}$

El informe del Fiscal de la Corte Suprema que fue elaborado por don Enrique Paillás explica como el Registro Civil con el sólo informe del Ministerio de Relaciones Exteriores canceló la nacionalidad del afectado, quien recurrió a la Corte Suprema

\footnotetext{
${ }^{6}$ Rol 4657-1999, 26 de enero de 2001, Libro Civil, N 6-10, recurso de Reclamo Nacionalidad, De la Fuente Badilla Juan Carol.
} 
alegando que su nacionalización argentina no había implicado renunciar a la nacionalidad chilena y que, además, debía aplicarse a su situación el artículo $11 \mathrm{~N}^{\mathrm{o}} 1$ de la Constitución, que dispone:

La causal de pérdida de la nacionalidad chilena . . . no regirá respecto de los chilenos que, en virtud de disposiciones constitucionales, legales o administrativas del Estado en cuyo territorio residan, adopten la nacionalidad extranjera como condición de permanencia en él o de igualdad jurídica en el ejercicio de los derechos civiles con los nacionales del respectivo país.

El Fiscal fue de la opinión que el recurrente no había perdido la nacionalidad y que por tanto debía acogerse su reclamación. El Fiscal argumentó también que el recurso se había interpuesto dentro de plazo porque se hizo valer inmediatamente de notificado de la medida del Registro Civil cuando solicitó su nueva cédula de identidad y que la causal del artículo $11 \mathrm{~N}^{\circ} 1$ se aplicaba en este caso porque los testigos presentados por el recurrente probaban los dichos de éste, en cuanto a que había solicitado la nacionalidad argentina para acceder a la beca de su doctorado.

El conocimiento por la Corte Suprema de estos recursos se da de manera excepcional, en calidad de jurado y deben ser resueltos por todos los ministros en pleN ${ }^{o}$ Sin embargo, la sentencia de la Corte se fundó en una resolución de siete páginas y su decisión fue dividida. El voto de mayoría concluye que el recurrente no renunció a la nacionalidad chilena para adquirir la argentina, quedando en los hechos con doble nacionalidad. Asimismo en la parte resolutiva, la Corte hizo ver la inconveniencia de que el Ministerio de Relaciones Exteriores informe estos casos al Servicio de Registro Civil sin analizar sus circunstancias particulares y la inconveniencia de que este último Servicio decrete la pérdida de la nacionalidad sin previa resolución judicial que así lo ordene. El voto de mayoría que suscriben los Ministros Alvarez, Faundez, Libedinsky, Ortiz, Benquis, Tapia, Chaigneau, Cury, Perez, Espejo, Yurac y Medina parece adecuado pues se basa en una interpretación de lo que se entiende por igualdad y de derechos civiles que comprende en su sentido amplio también el financiamiento del doctorado del recurrente. Igualmente parece correcta la advertencia de la Corte Suprema al Ministerio de Relaciones Exteriores y al Servicio de Registro Civil de evitar resolver estas materias de manera mecánica e irreflexiva y de arrogarse facultades judiciales.

Por su parte, el voto de minoría señaló que tanto el Ministerio de Relaciones Exteriores como el Servicio de Registro Civil se limitaron a cumplir sus deberes jurídicos. A este respecto señaló que por mandato constitucional se pierde la nacionalidad por adquirir una extranjera y que las pruebas del recurrente no fueron suficientes para acreditar la excepción del artículo $11 \mathrm{~N}^{0} 1$ ya que éste: "se nacionalizó argentino para el sólo efecto de mantener una beca que le financiaba sus estudios doctorales. En consecuencia, su conducta se vio motivada para obtener un beneficio netamente económico y, por lo mismo no puede pretender beneficiarse de una norma de carácter excepcional.” Fueron los Ministros Gálvez, Garrido, Marín, Rodríguez y Jordán quienes pronunciaron tal voto de minoría quienes declarando su conformidad con que estas materias tan relevantes sean resueltas por el Ministerio de RREE y el Servicio de Registro Civil. Además, confirman la aplicación de la excepción del artículo $11 \mathrm{~N}^{0} 1$ de acuerdo a una idea muy restringida de la igualdad y de los derechos civiles, como si estas nociones excluyeran los beneficios económicos o educacionales. 
Ruiz-Tagle - Jurisprudencia Corte Suprema 2001: Derecho Constitucional

En cambio, a nuestro juicio el objetivo de obtener financiamiento para un doctorado en el extranjero (por lo demás, un doctorado ya iniciado que quedaría inconcluso según cuenta el recurrente) debe quedar comprendido en la excepción del artículo $11 \mathrm{~N}^{\mathrm{0}}$ 1. Es discutible sin embargo si el recurrente optó por la nacionalidad argentina para permanecer en ese país, como dispone la constitución o si optó a la misma para completar sus estudios de doctorado.

\section{Acción de Protección}

Las acciones de protección durante el periodo examinado constituyen los casos más numerosos. Por eso, no sólo por su número sino también por su diversidad en cuanto a las derechos fundamentales invocados y las autoridades contra las cuales se recurre, es difícil explicar su desarrollo de una manera cronológica como se ha hecho en relación con las demás acciones incluidas en este comentario. Estimo conveniente en esta oportunidad usar una clasificación que desarrollé en un trabajo anterior sobre igualdad constitucional que distingue tres categorías y que puede servir para evaluar la contribución que supone la acción protección a los derechos fundamentales y a la democracia. ${ }^{7}$ Los criterios que se usaron para clasificar las acciones de protección se reducen a los siguientes: 1) acciones de protección dirigidas contra personas privadas; 2) acciones de protección dirigidas contra personas públicas de gobierno y administración, tales como municipalidades o personas que colaboran en la función ejecutiva; y finalmente; 3) acciones de protección contra personas que ejercen potestades jurisdiccionales, tales como árbitros, el contralor y otros entes jurisdiccionales. Usaremos entonces esta clasificación para nuestros comentarios del trabajo judicial en materia constitucional durante el año 2001.

\section{Acciones de protección dirigidas contra personas privadas}

En las causas que son objeto de este comentario no encontramos acciones de protección interpuestas en contra de personas privadas y que hayan sido acogidas por la Corte Suprema durante el periodo que se analiza. Probablemente ello se debe al estricto examen de admisibilidad aplicado por la Corte.

\section{Acciones de protección contra personas públicas de gobierno y administración}

El primer caso de protección del que nos impusimos durante el año 2001 se refiere a una persona pública que forma parte integral de la administración. Trata sobre la aplicación de una multa por parte de la Inspección Provincial del Trabajo de la ciudad de Concepción a la empresa Promather Ltda. ${ }^{8}$ La protección se fundó en la supuesta violación del acceso a la justicia comprendida en el debido proceso y en la prohibición a

\footnotetext{
7 Ver Ruiz-Tagle, Pablo, “Apuntes sobre la Igualdad Constitucional en Chile,” en Revista de la Universidad de Palermo, SELA 1999, Año 2000, Universidad de Palermo, Centro de Estudios de Postgrado en Derecho, Buenos Aires, Argentina.

${ }^{8}$ Rol 4383-2000, 14 de marzo de 2001, Libro Protecciones, No 2-3, recurso de protección, Sociedad Importador Promather Ltda. con Inspección Provincial del Trabajo de Concepción.
} 
ser juzgado por comisiones especiales conforme al artículo $19 \mathrm{~N}^{0} 3$ incisos 4 y 5 , $\mathrm{N}^{0} 16$ y $\mathrm{N}^{\circ} 24$ de la misma disposición constitucional que comprenden la libertad de trabajo y el derecho de propiedad respectivamente. La Corte de Apelaciones de Concepción declaró inadmisible la acción de protección considerando que:

el Recurso de Protección está concebido por el legislador para poner remedio a situaciones de gravedad, que requieren una resolución inmediata con relación fundamentalmente a hechos, no así a las declaraciones de derecho, esto es, en cuanto a la aplicación o no de una norma jurídica determinada, situación que debe ser resuelta por los Tribunales llamados a conocer de dichas situaciones y conforme al procedimiento establecido para ello.

Esta justificación de la declaración de inadmisibilidad fue desechada de manera tácita en la resolución de mayoría que resolvió la apelación ante la Corte Suprema. De hecho la Corte Suprema determinó en su sentencia que la fiscalización que realiza la Dirección del Trabajo de la legislación laboral sólo debe hacerse efectiva cuando se encuentre ante situaciones de infracción de la ley laboral de manera clara, precisa y determinada. En el caso que la Dirección del Trabajo y la Inspección del Trabajo se arroguen facultades para sancionar a los particulares en circunstancias diversas a las antes mencionadas, se viola el artículo 420 del Código del Trabajo que establece la competencia de los Tribunales del Trabajo y asimismo, se infringe el inciso cuarto del artículo $19 \mathrm{~N}^{\circ} 3$. La Corte Suprema sostuvo que en tal caso la Dirección del Trabajo se constituiría en una comisión especial proscrita por la Constitución. En concepto de la Corte Suprema, la Dirección del Trabajo sólo puede aplicar sanciones administrativas de manera excepcional y jamás puede ejercer facultades jurisdiccionales.

Un segundo caso de protección se refiere a un procedimiento para ocupar ciertos cargos públicos en la Municipalidad de Renca, que fue objetado por la Contraloría y que llevó a la recurrente, a alegar la supuesta violación de los números 3, inciso 4to. y el 24 del artículo 19 de la Constitución. ${ }^{9}$ La recurrente dirigió su acción contra la Municipalidad y la Contraloría. La Corte de Apelaciones de Santiago en fallo unánime acogió la protección en virtud de la doctrina que la propiedad también se extiende a las cosas incorporales, en este caso a las funciones que son propias de los cargos y a la permanencia en ellos, de las cuales han sido privados los recurrentes por disposición de la Municipalidad y de la Contraloría al no respetarse el procedimiento reglado para su provisión. La Corte de Apelaciones rechazó la alegación de que se habría infringido el acceso a la justicia y también rechaza la tesis de la Contraloría sobre la extemporaneidad de la acción. Incluso más, la Corte de Apelaciones dijo expresamente, que la Contraloría, al pedir la invalidación de los decretos de nombramiento de los funcionarios recurrentes y la Municipalidad al haber dictado dichos decretos actuaron de manera arbitraria e ilegal. La Corte Suprema confirmó la sentencia de la Corte de Apelaciones, pero rechazó la posibilidad de hacer valer el derecho de propiedad incorporal sobre el cargo y sostuvo que el derecho constitucional relativo a las funciones y empleos públicos está consagrado en el número 17 del artículo 19 y no es susceptible de recurso de protección. En consecuencia, alegar derecho de propiedad incorporal en este caso, significa confundir instituciones jurídicas diversas, esto es, la titularidad de un derecho con la propiedad. Según la Corte Suprema ello se traduciría en aceptar la acción protección para el caso del número 17 del artículo 19 lo que no procede en derecho. Lo curioso es que entonces no se entiende por qué se

\footnotetext{
${ }^{9}$ Rol 1921-2000, 12 de junio de 2001, Libro Protecciones, No 1-4, recurso de protección, Chernilo Muller Ely y
} otros con I. Municipalidad de Renca y Contraloría General de la República. 
confirmó la sentencia apelada que acogió el recurso en virtud del número 24 del artículo 19, ya que correspondía rechazar la acción de protección, ya que no existiría en opinión de la Corte un derecho constitucional que sirviese de fundamente a la acción de protección.

Un caso similar al anterior se refiere a la invalidación que el Alcalde de Peñaflor aplicó a un procedimiento para proveer ciertos cargos en su municipio, por orden de la Contraloría, invalidando los cargos otorgados. De esta manera un grupo de diez funcionarios recurrió en contra del Contralor General de la República. La Corte de Apelaciones resolvió a favor del derecho de propiedad de los cargos de los recurrentes señalando que existe un derecho que ya está incorporado en su patrimonio y argumentó además que Contralor excedió su competencia. La Corte Suprema revocó el fallo de la Corte de Apelaciones señalando que a pesar de que las municipalidades están exentas del trámite de toma de razón, ello no significa que la Contraloría no pueda ejercer las facultades de fiscalización que le otorga la Constitución. Respecto del derecho de propiedad que alegan los recurrentes, afirmó que "el $\mathrm{N}^{\circ} 24$ del artículo 19 de la Constitución Política de la República, no contempla una supuesta propiedad del empleo o función" y que este derecho se encuentra contenido en el número 17 del artículo 19, el cual se limita a asegurar la admisión a las ocupaciones, sin contemplar la permanencia en las funciones o empleos. Agregó que no se debe confundir la titularidad de un derecho con la propiedad sobre el derecho en sí. Por último, la Corte Suprema indicó que afirmar que la titularidad constituye un bien incorporal sobre el que existe una especie de propiedad implica dar una protección indirecta a derechos excluidos del artículo 20 de la Constitución.

Otro caso es el recurso interpuesto por la sociedad Racimec Internacional S.A contra el Tesorero Regional Metropolitano por el rechazo de la solicitud de reintegro de gravámenes, el cual asciende al 10\% del valor de los productos exportados. La Corte de Apelaciones acogió el recurso argumentando que la autoridad recurrida actuó en forma ilegal, excediendo su competencia, y conculcó el derecho de propiedad de la sociedad sobre el dinero correspondiente a los gravámenes. La Corte Suprema revocó la resolución sosteniendo que por la naturaleza de la materia no es procedente la acción cautelar ya que el derecho que se reclama no es indubitado y debe ser declarado en juicio de lato conocimiento. La misma sociedad recurrió posteriormente por una situación semejante en otras exportaciones realizadas. La particularidad de este nuevo caso es que tanto la Corte de Apelaciones como la Corte Suprema fallaron con textos de considerandos idénticos.

Existe una serie de tres casos en que se recurrió de protección en contra del Director Nacional del Instituto de Desarrollo Agropecuario (INDAP). Los recurrentes fueron tres funcionarios de dicho organismo que habían sido sancionados disciplinariamente en el ejercicio de sus cargos por el anterior director del INDAP. Las acciones se fundaron, en supuestas afectaciones a los derechos fundamentales del debido proceso (art. $19 \mathrm{~N}^{\circ}$ 3) y de propiedad (art.19 $\mathrm{N}^{\circ} 24$ ). Los tres casos fueron acogidos por la Corte de Apelaciones de Santiago y rechazados por la Corte Suprema con argumentaciones muy similares respectivamente. Las sanciones disciplinarias fueron impuestas, luego de un proceso sumario llevado a cabo por la Contraloría, mediante una resolución definitiva dictada del Director del INDAP.

La Corte de Apelaciones acogió los recursos señalando que se afectó el debido proceso. En efecto, el Director del INDAP, al resolver la sanción, no ponderó ni analizó los antecedentes del sumario, limitándose a aplicar automáticamente lo propuesto por la 
REJ - Revista de Estudios de la Justicia - No 3 - Año 2003

Contraloría. La Corte Suprema rechazó las acciones argumentando que no se había afectado el debido proceso, puesto que la resolución fue tomada sobre la base de los antecedentes reunidos en el sumario realizado por la Contraloría, lo que no constituye un acto arbitrario.

Algo sorprendente en las sentencias es que en dos de los tres casos (Graciela Flores con Director INDAP y Cesar Toledo con Director INDAP) se apeló al derecho a la honra como posible garantía afectada ante una decisión arbitraria sobre el cargo, aún cuando las partes no invocaron este derecho fundamental. Otro punto destacable es que en los fallos existen párrafos absolutamente idénticos en los considerandos de las sentencias.

En cuanto al tercer caso (José Candia v. Director INDAP) la Corte de Apelaciones determinó que se había afectado el derecho de propiedad sobre la estabilidad en el empleo a consecuencia de una sanción de destitución respecto de conductas no expresamente descritas y determinadas por la ley. Por el contrario, la Corte Suprema señaló que el derecho a la estabilidad en el empleo sólo perdura mientras exista un buen desempeño en el cargo, al que por lo demás no corresponde el derecho de propiedad y por tanto, no es susceptible de recurso de protección.

En otro caso don Roberto Pasten Cuellar y otros y don Roberto Corbeaux Cruz en representación de la empresa -Manganesos Atacama S.A.- interpusieron, respectivamente, acciones constitucionales de protección en contra del Director de Salud de Coquimbo, ${ }^{10}$ porque éste había dictado una resolución que afectaba los derechos fundamentales de los números 3, 4, 21 y 24 del artículo 19 de la Constitución. La Corte de Apelaciones de La Serena, en voto dividido de mayoría, luego de conocer la defensa del funcionario recurrido, resolvió acoger parcialmente el recurso en cuanto su acción produjo una obstrucción administrativa en la empresa demandante, pero declaró inadmisible y rechazó el recurso de protección porque aunque el Director de Salud había incurrido en errores en su actuación no se constituyó como comisión especial, ni afectó el derecho de propiedad, ni impuso cargas a la recurrente en contravención al mandato constitucional. El voto disidente, del ministro Zepeda, estuvo por rechazar el recurso porque en su opinión la actuación de los funcionarios de salud sólo tuvo por objeto verificar el cumplimiento de las obligaciones de salud y medioambientales de la recurrente. La Corte Suprema rechazó la acción de protección haciendo suyas las argumentaciones del voto disidente en cuanto a que el Servicio de Salud de Coquimbo había actuado en la esfera de sus atribuciones y por ello no podían considerarse como afectados de modo ilegítimo los derechos fundamentales de la recurrente. Para esos efectos citó los artículos 67 y 178 del Código Sanitario que otorgan facultades al órgano recurrido. La sentencia de la Corte Suprema también discurrió sobre la improcedencia de la alegación de la cosa juzgada en materia de recursos de protección por ser una acción cautelar que se refiere a situaciones de hecho.

En otro caso, se recurrió de protección en contra de la Universidad del Bío-Bío por parte de un arrendatario y varios trabajadores de un predio en razón de que dicha institución colocó un portón que impedía a los demandantes ingresar al fundo, lo que según ellos constituyó un acto arbitrario e ilegal. La Corte de Apelaciones de Chillán

\footnotetext{
10 Rol 2274-01, 10 de julio de 2001, Libro Protecciones, № 1-5, recurso de protección, Caratulado Manganesos
} Atacama S.A. con Servicio de Salud Coquimbo. 
Ruiz-Tagle - Jurisprudencia Corte Suprema 2001: Derecho Constitucional

rechazó la acción, en primer lugar, porque fue interpuesta en forma extemporánea. En segundo lugar, señaló que el portón fue colocado en un terreno que es propiedad de la Universidad y los recurrentes no alegaron derecho alguno sobre el paso en conflicto. La Corte Suprema revocó la sentencia apelada argumentando que no había antecedentes que permitieran decidir sobre la extemporaneidad del recurso y señalando que la acción de la Universidad alteraba una situación de hecho preexistente desde tiempos inmemoriales, lo que afectaba el art. 19 o 24 de la Constitución, aún cuando el portón se encontrara dentro de la propiedad de la Universidad.

Por último, uno de los casos de mayor relevancia tanto a nivel constitucional como en la opinión pública, es el recurso de protección interpuesto por diversas organizaciones pro vida contra el Instituto de Salud Pública y la Ministra de Salud, por haber autorizado la comercialización del fármaco Postinal o "Píldora del día después". Los recurrentes afirmaron que dicho fármaco era abortivo, ya que el medicamento puede evitar la implantación del óvulo fecundado en el útero de la madre, con lo que se puede impedir embarazos no deseados. Por su parte, los recurridos argumentaron que el medicamento tiene una finalidad anticonceptiva y que su venta se orienta a evitar el aborto provocado por la falta de medios para la planificación familiar o el uso de anticonceptivos. Señalaron a su vez que una vez iniciado el proceso de fecundación, implantación o anidación del embrión, el método pierde totalmente su efectividad. Su explicación también dio cuenta que los preparados farmacéuticos de tipo anticonceptivo actúan con las mismas bases del Postinal, cambiando solamente su posología y que la comercialización del producto no obliga a nadie a su uso. La Corte de Apelaciones rechazó el recurso con voto disidente, argumentando la falta de legitimación activa de los recurrentes, ya que estos serían "sujetos indefinidos y faltos de la concreción indispensable que la ley exige para ser titulares de la acción de protección". Además la Corte de Apelaciones argumentó que: "los informes y estudios científicos ...son ajenos a esta acción de protección desde que requerirían una instancia de lato conocimiento...".

La Corte Suprema revocó el fallo con una opinión de mayoría y un voto disidente de los Ministros señores Yurac y Kokish. Respecto de la legitimación activa la Corte Suprema señaló que en verdad en este caso no se ha recurrido por seres indefinidos, sino, seres en desarrollo que surgirán a la vida legal con todos los atributos de las personas, además, si bien el sujeto no existe en el momento de formularse la amenaza, lo que impide recurrir por cualquiera a su nombre, ciertamente existirá al momento previsto para el cumplimiento de la amenaza, razón por lo cual merece la salvaguardia prevista por el recurso de protección. Respecto del momento en que debe otorgarse la protección constitucional al embrión, la Corte Suprema señaló que la fertilización es un proceso continuo que no puede separarse en etapas, por lo que el embrión es digno de protección constitucional y legal desde su concepción hasta el nacimiento. Por tanto, si el medicamento puede impedir la implantación del embrión en el útero es abortivo y por consiguiente debe concluirse que la autorización de la venta del fármaco constituye un acto ilegal. El fallo de mayoría sin embargo no se hizo cargo de ponderar el potencial efecto abortivo de la sustancia que es objeto del recurso y la circunstancia alegada por la recurrida que se trata de dosis diversas a las que usualmente se usan para anticonceptivos comunes. Tampoco ponderó la autonomía y la libertad de la persona que ingiere esta sustancia con la protección que la constitución establece respecto del que está por nacer. Finalmente, nada dijo el fallo de mayoría sobre la deferencia que los tribunales deben tener respecto de los organismos técnicos de salud. 
Por su parte, el voto disidente argumentó que la acción de protección no es procedente para declarar, constituir o extinguir derechos ni para introducirse en el estudio científico como sucedió en este caso, ya que eso es materia de un juicio de lato conocimiento. Agregó también que el estatuto jurídico del embrión no puede ser determinado por una acción constitucional de carácter cautelar. Entre el fallo de mayoría y la opinión disidente parece haberse producido un diálogo de sordos. En definitiva, se preparó el camino para el caso que lo siguió con el nombre de Postinal II. Este segundo caso en definitiva significó aprobar la venta de un fármaco muy semejante al que había sido prohibido y al no dar cuenta del rechazo y luego dar cabida a la aprobación en estas cuestiones tan relevantes se afectó el prestigio de la Corte como un órgano del Estado que da razones coherentes para justificar su actuación.

\section{Acciones de protección contra personas que ejercen potestades jurisdiccionales}

El señor Alejandro Gordillo interpuso acción de protección contra el juez del Cuarto Juzgado Civil de San Miguel por haber ordenado el desalojo de una propiedad que ocupaba, vulnerando el derecho de acceso a la justicia del $19 \mathrm{~N}^{\circ} 3$ y el derecho de propiedad del artículo $19 \mathrm{~N}^{0} 24$ de la Constitución. ${ }^{11}$ En su informe a la Corte de Apelaciones, el juez recurrido demostró las innumerables medidas dilatorias y los diversos incidentes que promovió el recurrente en los autos para demorar el proceso. La Corte de Apelaciones de San Miguel rechazó la acción de protección señalando expresamente que la supuesta transacción que invocó en su favor el recurrente es un documento que ha sido controvertido en autos, cuya validez y efectos no pueden establecerse por la vía de la protección. La Corte Suprema en opinión unánime confirmó la sentencia apelada y ordenó suprimir todos sus considerandos por declarar inadmisible la protección sustentada en ausencia de un derecho preexistente e indubitado. En opinión de la Corte Suprema, al estar sometido al conocimiento jurisdiccional el desalojo, a que estaba afecto el recurrente no procede revertir la decisión judicial por medio de una acción de protección y por eso declaró esta acción como inadmisible. Se trata de una decisión que parece bien fundada en derecho porque existía un procedimiento común que había sido legalmente tramitado.

\section{Acción de Amparo Económico}

Son sólo cinco los casos de amparo económico que se han tenido a la vista para este comentario. El primero es un caso de amparo económico contra entidades públicas de gobierno que la firma Electricidad Gobantes S.A. interpuso contra el Servicio de Impuestos Internos porque en la página web de dicho servicio se dio aviso que el crédito fiscal de esta empresa podía ser rechazado de una manera que, en opinión de la recurrente, constituye un atentado contra el artículo $19 \mathrm{~N}^{\mathrm{o}} 21$ de la Constitución. ${ }^{12}$ La Corte de Apelaciones de Santiago, luego de analizar las facultades que tiene el Servicio de Impuestos Internos, señaló que la medida que tomó excedió el ámbito de la fiscalización y

\footnotetext{
11 Rol 2190-2001, 17 de julio de 2001, Libro Protecciones, No 3-5, recurso de protección, Alejandro Gordillo Gordillo con Sr. Juez. del Cuarto Juzgado Civil de San Miguel.

12 Rol 2036-2001, 14 de junio de 2001, Libro Civil, No 1-4, recurso de protección, Electricidad Gobantes S.A. con Director del S.I.I.
} 
Ruiz-Tagle - Jurisprudencia Corte Suprema 2001: Derecho Constitucional

se transformó en una verdadera obstrucción, ya que al decir que el crédito fiscal de la recurrente por existir suplantación de RUT "podría ser objetado por el SII" hace que la firma Electricidad Gobantes S.A. sea objeto de "objeciones en el normal desarrollo de la práctica impositiva." La Corte Suprema en voto de mayoría confirmó la sentencia de alzada agregando a la sentencia la frase: "ya que (el SII) recomienda en forma directa que no se realicen operaciones con la recurrente, en lugar de decir que no se haga con quién la suplanta." En este caso hay también una prevención del Ministro Gálvez que está por no eliminar los párrafos consultados porque en su opinión no corresponde hacerlo en un recurso de amparo económico, sino que en el recurso de protección.

El segundo caso de amparo, caratulado Alimar con Subsecretaría de Pesca, ${ }^{13}$ se recurrió para que la Corte revoque resoluciones de la autoridad pesquera por las cuales se impidió que embarcaciones de la recurrente participen en la pesca del jurel y fauna acompañante en las regiones XI y XII, lo que supuestamente infringiría el artículo 19 número 21 de la Constitución. En este caso la acción de amparo económico se dedujo conjuntamente con acciones de protección y la sentencia de la Corte de Valparaíso rechazó el amparo económico por tratarse justamente de una materia de protección y, asimismo se fundó en una supuesta distinción que existiría entre el inciso primero y el segundo del número 21 del artículo 19, estando el primero según la Corte referido a todas las personas y el segundo destinado para que se alegue por la conducta de organismos estatales. La Corte Suprema, de manera correcta a nuestro entender, rechazó la idea de que por ser materia de protección no pueda conocerse un amparo económico conjuntamente y, además, criticó la distinción hecha por la Corte de Valparaíso entre los dos incisos del número 21 del artículo 19. Asimismo, con respecto al fondo, justificó las resoluciones que impiden el ingreso de nuevas embarcaciones a las actividades pesqueras en las regiones XI y XII, en el hecho que las autoridades pesqueras intentaron así preservar y conservar los recursos hidrobiológicos según la Ley General de Pesca y Acuicultura.

El tercer caso de amparo económico, caratulado Sociedad Comercial Rojas Hnos. Oy $D$ Limitada con Director Regional de Vialidad VI Región, ${ }^{14}$ se refirió a un letrero de propaganda que un organismo público ordenó retirar en virtud de lo dispuesto en el artículo 50 del DFL 850 de 1997 y que según la recurrente infringiría el artículo 19 en sus números 6, 7, 21 y 24 de la Constitución. La Corte de Apelaciones de Rancagua rechazó el recurso por existir normas legales que respaldan la decisión de vialidad. La Corte Suprema en decisión unánime, confirmó la sentencia de la Corte de Rancagua y cita a mayor abundamiento los artículos 38 y 52 del DFL 850 de 1997 y 5 del Decreto Supremo 1.139 para respaldar la acción de la Dirección de Vialidad, sin perjuicio de que el recurrente accione por la vía ordinaria según las reglas generales.

En un cuarto caso de amparo económico, caratulado Constructora Santa María del Campo con Director de SERVIU,"15 se alegó sobre un contrato de obra terminado por la autoridad. El contrato involucraba una empresa contratista que recurrió porque se vio

\footnotetext{
${ }^{13}$ Rol 2421-2001, 17 de julio de 2001, Libro Protecciones, No 3-5, recurso de amparo económico, Alimentos Marinos S.A “Alimar" con Subsecretaría de Pesca.

14 Rol 3226-01, 2 de octubre de 2001, Libro Protecciones, No 1-4, recurso de amparo económico, Sociedad Comercial Rojas Hnos. Oy D Limitada con Director Regional de Vialidad VI Región.

15 Rol 3796-01, 29 de octubre de 2001, Libro Protecciones, N 4-4, recurso de amparo económico, Sociedad Constructora Santa María del Campo Ltda. con Director de Serviu de la Región de Coquimbo.
} 
REJ - Revista de Estudios de la Justicia - No 3 - Año 2003

afectada por las resoluciones del SERVIU y de la Contraloría Regional en su libre iniciativa económica. La sentencia de la Corte de Apelaciones de La Serena afirmó que el atraso en las obras de la recurrente no es injustificado y por eso la resolución que, de acuerdo a las bases, declaró resuelto anticipada y administrativamente el contrato, se ajustó a derecho. La Corte Suprema abunda en motivos adicionales para el rechazo de la acción de amparo económico; declaró que en nada afecta la actividad de construcción de la recurrente la medida impugnada que es una resolución simplemente fundada en la resolución de un contrato no cumplido. Los dos últimos considerandos de la sentencia intentan explicar la verdadera diferencia entre la protección y el amparo económico y argumenta que falta un vínculo de causalidad entre la actuación que se reprocha y el perjuicio causado. Esta argumentación parece corresponder a un razonamiento de derecho privado que resulta insuficiente porque no se explica porqué no existiría dicho nexo causal en este caso.

Finalmente, entre los casos de amparo económico se encuentra el asunto caratulado Empresa Eléctrica Guacolda S.A. con Ministerio de Economía, Fomento y Reconstrucción. ${ }^{16}$ En este caso se pidió declarar contrarias al artículo $19 \mathrm{~N}^{\mathrm{o}} 21$ de la Constitución las resoluciones del Ministerio de Economía 79 y 80 porque éstas valorizaron las transferencias entre empresas y modificaron el régimen de esta actividad que está consagrado en el DFL 1 de una forma que es contraria a la libertad económica. La Corte de Apelaciones de Santiago, en decisión unánime, rechazó el recurso de amparo económico teniendo presente que la generación de energía, su transporte y distribución constituyen un servicio público que está regulado por normas de derecho público que tratan de preservar la seguridad del servicio. También argumentó que entre las potestades legales y reglamentarias del Ministerio de Economía se encuentran aquellas que facultan a esta autoridad para dictar las resoluciones impugnadas. La Corte Suprema confirmó la decisión de la Corte de Apelaciones y rechazó el recurso alegando que con las medidas tomadas por el Ministerio de Economía no se pone "freno o impide el desarrollo de la actividad económica, aún cuando en un caso tenga incidencia en los ingresos que pueda obtener [la recurrente] de la transferencia de energía . . . el derecho mismo al desarrollo de la actividad económica no se ve afectado." Esta consideración que la Corte Suprema hace explícita en sus considerandos 8 y 9 de la sentencia permite, por lo demás, distinguir lo que es propio de la acción de amparo económico de otras acciones constitucionales que le son próximas, como es el caso del recurso de protección, o incluso el procedimiento de reclamación por expropiación. La sentencia de la Corte Suprema termina con la referencia que ya hemos mencionado a la ausencia de vínculo causal, que tampoco en esta ocasión se explica.

\section{E. Acción de Amparo}

Un solo caso de amparo se ha tenido a la vista en este comentario, en el asunto que ha sido caratulado María Tecay Paillan con el Juez del Tercer Juzgado de Letras de Magallanes. ${ }^{17}$ La acción de amparo fue deducida a favor de doña María Tecay Paillan que se encontraba recluida y procesada y pedía se le redujera su fianza para así acceder a la

\footnotetext{
16 Rol 3797-01, 29 de octubre de 2001, Libro Protecciones, No 4-4, recurso de amparo económico, Empresa Eléctrica Guacolda S.A. con Ministro de Economía, Fomento y Reconstrucción.

17 Rol 1693-2001, 4 de junio de 2001, Libro Criminal, № 1-8, recurso de amparo, María Tecay Paillan con Sr. Juez del Tercer juggado de Letras de Magallanes.
} 
Ruiz-Tagle - Jurisprudencia Corte Suprema 2001: Derecho Constitucional

libertad provisional. La resolución del juez fue confirmada por unaminidad por los ministros la Corte de Punta Arenas. La recurrida alega que el juez aplico el artículo 41(44) de la Ley de Cuentas Corrientes y Cheques de una manera que afecta la garantía constitucional de la libertad provisional establecida en el artículo $19 \mathrm{~N}^{\mathrm{o}} 7$ y el artículo 5 de la Constitución en relación con los artículos 5 y 7 del Pacto de San José de Costa Rica que han adquirido rango constitucional y prohíben la prisión por deudas. El voto de mayoría estimó que el artículo invocado por el juez del crimen para imponer la fianza y negar la libertad se encuentra tácitamente derogado por aplicación del artículo 52 del Código Civil y por haberse adoptado el artículo 19 número 7 que otorga a todos el derecho a la libertad provisional. En voto de minoría el ministro Chaigneau hizo suya la tesis del juez recurrido en el sentido que no procede acceder al amparo recurrido para otorgar el beneficio de la libertad provisional. Esta decisión configura una situación diferente a simplemente haber negado el beneficio de la libertad provisional que establece para todo persona la garantía constitucional del artículo $19 \mathrm{~N}^{\mathrm{0}}$ 7. Por eso este caso parece estar en el límite de afectar el derecho a la libertad en su esencia, porque tanto el juez como la Corte no negaron la libertad, sino que fijaron una suma que motivó el alegato de la recurrente.

\section{F. Acción de Inaplicabilidad}

Entre las sentencias de inaplicabilidad que se han tenido a la vista se incluye los casos Gaete y el caso Sáez con el Instituto de Normalización Previsional (INP) que son muy semejantes en cuanto a su resolución. ${ }^{18}$ En ambos casos se recurrió para que se realice el cálculo de una pensión de una manera determinada. El señor Gaete y la señora Sáez en causas separadas alegaron que el cálculo realizado por el INP afecto la igualdad ante la ley, la igual distribución de las cargas públicas y el derecho de propiedad según dispone el artículo 19, números 2, 20 y 24 de la Constitución. Para fundamentar las respectivas decisiones de rechazo a la acción de inaplicabilidad, la Corte Suprema hizo suyo el informe del Fiscal y citó dos fallos que definen la igualdad constitucional como una prohibición de establecer diferencias arbitrarias, para luego argumentar que en este caso no estaría afectada dicha garantía. Las sentencias citadas son C.S., 25-11-1970, R.D.J., t.67, sec.1, pag.530 y C.S., 15-6-1988, R.D.J., t.85, sec.5a., p.97. (en el párrafo final de los comentarios referidos a la inaplicabilidad me refiero a las dudas que tengo sobre la cita de esta jurisprudencia). En este caso, la Corte Suprema también rechazó las argumentaciones de una supuesta diferencia en las cargas públicas que habría afectado al recurrente. Finalmente, con respecto al derecho de propiedad acepta la tesis del INP en el sentido que la propiedad sobre la pensión se refiere al derecho a jubilar y al monto global de la jubilación pero no incluye los sistemas de actualización, reajustabilidad o al incremento de éstas.

En un tercer caso de inaplicabilidad entre dos personas privadas la recurrente doña Carmen Cáceres demandó a Forestal Celco S.A. para que se declararen inaplicables diversas disposiciones del DL 2695 sobre regularización de la propiedad raíz. ${ }^{19}$ La Corte Suprema, en voto de mayoría, declaró inadmisible la inaplicabilidad por estimar que por esta vía no se puede invalidar una situación o derecho ya incorporado al patrimonio, como

\footnotetext{
18 Rol 3494-99, 19 de enero de 2001, Libro Civil, No 9-10, recurso inaplicabilidad, Gaete Quezada Miguel Angel de Instituto Normalización Previsional, y Rol 3495-99, 29 de enero de 2001, Libro Laboral, No 9-10, recurso de inaplicabilidad, Sáez. Luco Sonia con Instituto Normalización Previsional.

19 Rol 3612-96, 16 de marzo de 2001, Libro Civil, N 3-6, recurso de inaplicabilidad, Cáceres Blandida del Carmen.
} 
REJ - Revista de Estudios de la Justicia - No 3 - Año 2003

es el caso del dominio ya inscrito de la parte demandada. Sobre esta materia también es interesante consignar que el Fiscal en su informe recomendó que esta materia debe discutirse en un juicio civil reivindicatorio y que no es propiamente una materia constitucional. Lo que llama la atención en este caso es la similitud en cuanto a la argumentación y la redacción de la sentencia de la Corte con los utilizados en los casos Gaete y Sáez. con INP y Cáceres con Forestal Celco, previamente comentados.

Un cuarto caso de inaplicabilidad se refirió a la Ley 19593 que sirvió para decretar la suspensión del derecho de inscribir nuevos taxis que inició Sáez con Fisco por infringir los números 2, 21, 22 y 24 del artículo 19 de la Constitución. ${ }^{20}$ El voto de mayoría desestimó la inaplicabilidad aduciendo argumentos semejantes a los casos anteriores que se han mencionado en Gaete y Sáez con INP y Cáceres con Forestal Celco, y citando incluso los mismos fallos invocados en relación con la igualdad que se mencionaron en Gate con INP. Se agregan consideraciones relativas a la identificación de la suspensión con la restricción legislativa que autoriza la Constitución y también la asimilación de las causales de salud al supuesto efecto de contaminación que provocan los taxis, las que resultan altamente controvertidas. Sin embargo, se agregan también nuevos argumentos y consideraciones, particularmente en el voto de minoría que hace de esta sentencia una de las más rescatables y completas del periodo 2001. Por ejemplo, el voto de minoría de los ministros Jordán y Pérez se funda en las doctrinas sobre la primacía de la persona humana sobre el Estado, la mayor importancia de los nueve primeros artículos sobre los demás de la Constitución y la noción de orden público económico del Profesor José Luis Cea en su Tratado de la Constitución de 1980.21 Todas estas doctrinas resultan muy controvertidas ${ }^{22}$ y aunque la sentencia se apoya en ellas el fondo de su argumentación es diverso. Porque, sin perjuicio de esta invocación doctrinaria que refuerza la parte resolutiva del voto de minoría, el sustrato de la opinión de los ministros Jordán y Perez lo constituye la idea que la suspensión por dos años que establece le ley 19.953 de inscribir nuevos taxis no puede ser considerada una restricción de aquellas que autoriza la Constitución. El voto de minoría concluye que al no autorizar la inscripción de nuevos taxis se ha afectado la igualdad ante la ley, la libre iniciativa económica y la no discriminación en la imposición de cargas, como también el libre acceso a la propiedad y el derecho de propiedad. También el voto de minoría estima que la suspensión es contraria a los incisos 4 y 5 del artículo 1 de la Constitución.

En un quinto caso caratulado Sernap con Fuentes y otro ${ }^{23}$ se requiere la declaración de inaplicabilidad de una serie de disposiciones de la Ley 18.892 que establecen vedas de pesca y multas para su infracción, y se razona de manera semejante al caso Sáez con Fisco. El recurrente en este caso invocó para fundamentar su inaplicabilidad diversas disposiciones de la Constitución, entre ellas los artículos 3, 5, 19 número 21, 23, 60 y 73. Sin embargo, la Corte Suprema rechazó la inaplicabilidad argumentando que ninguna de esas disposiciones constitucionales había sido infringida por la Ley 18.892. Incluso más, la Corte Suprema argumentó que las disposiciones que se pretendía declarar inaplicables se fundaban en los deberes de protección de la naturaleza que impone el artículo 19 número

\footnotetext{
${ }^{20}$ Rol 862-00, 21 de junio de 2001, Libro Civil, No 7-10, recurso de inaplicabilidad, Sáez con Fisco de Chile. 21 Cea Egaña, José Luis, Tratado de la Constitución de 1980 (Santiago: Ed. Jca. de Chile, 1988).

22 Ver Ruiz-Tagle, Pablo, "Principios Constitucionales del Estado Empresario," Revista de Derecho Público v 62 p 48-66 (2000) y Ruiz-Tagle, Pablo, "Una Dogmática General para los Derechos Fundamentales en Chile," Revista de Derecho Público v 63 p 179-200 (2001).

23 Rol 3946-99, 6 de julio de 2001, Libro Civil, № 1-13, recurso de inaplicabilidad, Sernap Fuentes y otro.
} 
Ruiz-Tagle - Jurisprudencia Corte Suprema 2001: Derecho Constitucional

8 de la Constitución y citó a este respecto la jurisprudencia anterior, (cfr. C. Suprema, 19 de diciembre 1985, R.D.J., T,82, SEC.5, P.262). La Corte también argumentó que los artículos 110, 124 y 165 impugnados constituían formas de cumplir con la Convención de Naciones Unidas sobre Derecho del Mar, tratado publicado en el Diario Oficial con fecha 18 de noviembre de 1997. Por eso, junto con rechazar la inaplicabilidad de la Ley 18.892, la Corte anunció su doctrina más general con respecto a los tratados que resume del modo siguiente:

los tratados internacionales sólo crean derechos y obligaciones entre los Estados contratantes y no son en si mismo fuentes del derecho interno, es menester para que produzcan sus efectos, que sus disposiciones sean introducidas en el orden jurídico nacional por medio de un acto expreso. Conforme a nuestra legislación es necesario que exista aprobación legislativa, que se promulgue por decreto del Presidente de la República y se proceda a su publicación en el Diario Oficial. Llenados dichos requisitos deben cumplirse y llevarse a efecto como ley. Como la Convención de Naciones Unidas sobre el Derecho del Mar fue sometida a dicha tramitación tiene fuerza de ley. Además,...del examen de sus preceptos aparece que la finalidad que persigue (la Convención citada) es la preservación de la naturaleza y la conservación del patrimonio ambiental, términos que el constituyente ha empleado al concebir y consagrar en el artículo 19 de la Carta Fundamental determinados derechos esenciales que emanan de la naturaleza humana y que los órganos del Estado tienen el deber de respetar y promover.

En opinión de la Corte Suprema, las disposiciones de la Ley 18.892 constituyen una regulación al derecho a desarrollar cualquier actividad económica, sin implicar una privación del dominio, conformando un sistema jurídico destinado a la protección de diversas especies hidrobiológicas, que se dictaron para dar cumplimiento a las obligaciones que el Estado de Chile asumió y que se encuentran contenidas en la Convención de las Naciones Unidas sobre el Derecho del Mar.

Es entonces nuestra conclusión que el razonamiento de este fallo parece bien fundado y es uno de los mejor resueltos del periodo porque armoniza de manera expresa diversas disposiciones constitucionales y legales de derecho interno con disposiciones emanadas de los tratados internacionales y lo hace por medio de una interpretación judicial ponderada y razonable. ${ }^{24}$

En un sexto caso de inaplicabilidad caratulado Garrido Tudela María y otros ${ }^{25}$ se recurre contra el artículo 26 de la Ley 18.953 sobre Tribunales Electorales por no contemplar la doble instancia o apelación. El voto de mayoría hace suyo el principio de especialidad de la competencia de los Tribunales Electorales y declara expresamente que los artículos 79 y 80 sólo permiten deducir inaplicabilidad contra las resoluciones de Tribunales sometidos a la tuición de la Corte Suprema, caso en el cual no se encuentra los Tribunales Electorales por mandato de la Constitución. En cambio, el voto de minoría que suscriben los ministros Jordán, Cury y Juica, aunque también está por declarar inadmisible este caso de inaplicabilidad por no existir gestión pendiente, deja constancia que la Corte Suprema sí puede conocer de las resoluciones de los Tribunales Electorales mediante esta vía procesal. Según el voto de minoría el hecho que la Constitución haya

\footnotetext{
${ }^{24}$ En este mismo número se publica el comentario que el profesor Correa ha hecho a este fallo, p ... (n. de los editores).

${ }^{25}$ Rol 2838-2000, 3 de agosto de 2001, Libro Civil, No 1-7, recurso de inaplicabilidad, Garrido Tuleda María y otros.
} 
REJ - Revista de Estudios de la Justicia - No 3 - Año 2003

establecido una independencia y especialidad muy marcada de los Tribunales Electorales, se refiere sólo a la imposibilidad de ejercer las facultades disciplinarias y económicas y no a las conservadoras, siendo estas últimas las que se ejercen en la inaplicabilidad. Por eso, la doctrina del voto de minoría parece correcta porque se funda en que la inaplicabilidad corresponde al ejercicio de las facultades conservadoras de la Corte Suprema.

Finalmente, el séptimo caso de inaplicabilidad, caratulado Jorge Oshnsenius V argas con Serv. Salud Metrop. Occidente, ${ }^{26}$ se refiere a la responsabilidad por los gastos médicos del recurrente y las disposiciones de la Ley 10.383 y el DL 2.763 que limitan esa responsabilidad respecto de los servicios públicos de salud por hacer sus bienes inembargables y por establecer el privilegio de pobreza. El recurrente alegó que estas disposiciones infringen los números 2, 3, y 21 del artículo 19 de la Constitución. El informe del Fiscal recomienda el rechazo del recurso porque los Servicios de Salud actúan de manera coordinada para hacer efectivo los números 8 y 9 del mismo artículo 19 que invoca el recurrente. Una vez más la Corte Suprema cita las sentencias C.S., 25-11-1970, R.D.J., t.67, sec.1, pag.530 y C.S., 15-6-1988, R.D.J., t.85, sec.5a., p.97 para argumentar que la igualdad constitucional permite hacer diferencias que no sean arbitrarias y que dicho principio exige la generalidad de la norma y un trato igual en circunstancias semejantes. La inaplicabilidad en este caso es rechazada porque se estima que el recurrente ha podido ejercer su derecho a defensa consagrado en el número 3 del artículo 19 y porque las normas recurridas no son contrarias a la igualdad constitucional.

Ahora bien, tal como lo anunciamos, es nuestra opinión que la sentencia de inaplicabilidad del año 1970 no debería ser citada para fundamentar decisiones actuales de la Corte Suprema porque corresponde a un caso sometido al régimen de la Constitución de 1925. Por su parte, el caso citado del año 1988 tampoco debería citarse porque corresponde al periodo pre-constitucional anterior a la vuelta a la democracia que se inicia en marzo de 1990. Las materias de igualdad en la Constitución vigente tienen un tratamiento diverso a la Constitución de 1925 y durante el periodo pre-constitucional que va de 1973 a 1990 no se puede hablar de protección del principio de igualdad, quizá el más afectado por la ausencia de instituciones democráticas. Por eso creemos que las sentencias de acciones o recursos constitucionales no deberían mencionar jurisprudencia anterior a 1990 en los casos futuros, sobre todo si es que ya existe una abundante jurisprudencia constitucional chilena que reconoce este principio durante el periodo constitucional democrático.

\section{G. Casación en el Fondo}

Son sólo dos los casos de casación que se han tenido a la vista para este trabajo. En el primero de ellos, la Corte Suprema dictaminó la nulidad de un matrimonio celebrado en el extranjero por estar uno de los cónyuges unido por vínculo matrimonial no disuelto de acuerdo a la Ley de Matrimonio Civil Chilena. ${ }^{27}$ La sentencia de la Corte Suprema anuló un acto jurídico celebrado en país extranjero y, por consiguiente, dio efecto extraterritorial sus disposiciones. En estas materias de derecho internacional

\footnotetext{
${ }^{26}$ Rol 4865, 24 de octubre de 2001, Libro Civil, No 8-12, recurso de inaplicabilidad, Jorge Oschsenius Vargas con Serv. Salud Metropolitano Occidente.

${ }^{27}$ Rol 2232-00, 25 de enero de 2001, Libro Civil, No 7-10, recurso casación forma y fondo, Pardo con Burger.
} 
privado, sobre las que la Constitución no se pronuncia, aunque esté presente el interés público chileno, debería darse a nuestro juicio un mayor peso específico a la voluntad de las partes. ${ }^{28}$

El segundo caso consistió en una casación en la forma y en el fondo referido al monto de la indemnización en un procedimiento de expropiación. ${ }^{29}$ El recurso de casación en la forma fue declarado inadmisible porque según la Corte Suprema la causal invocada, al tratarse de un procedimiento especial, no correspondía ser aplicada. Sin embargo, el recurso de casación en el fondo fue acogido porque la sentencia recurrida negó lugar a la indemnización desconociendo el derecho del recurrente de reclamar la indemnización del daño patrimonial efectivamente causado por la expropiación, según dispone el artículo $19 \mathrm{~N}^{\mathrm{o}} 24$ de la Constitución. Según la Corte Suprema la sentencia recurrida hizo una interpretación errónea y por ello se dictó sentencia de reemplazo en estos autos.

\section{H. Conclusiones}

$\mathrm{Al}$ concluir estos comentarios sobre los fallos constitucionales relevantes del año 2001 es posible extraer algunas conclusiones generales:

1. Existe una tendencia en la redacción de las sentencias a transcribir extractos de fallos anteriores similares y "copiarlos y pegarlos" en sus considerandos sin mayor análisis ni razonamiento. Esto es patente en algunos fallos de protección y de inaplicabilidad.

2. Otra tendencia clara en las sentencias analizadas es la de fallar a favor del Estado. Esto se demuestra en el hecho de que de un total de 25 acciones en contra de entidades estatales (de índole administrativa y jurisdiccional), sólo en 8 de ellas fueron acogidas pretensiones particulares, es decir, sólo un tercio.

3. Los derechos fundamentales más recurridos vía protección fueron el derecho a no ser juzgados por comisiones especiales (19 $\mathrm{N}^{\circ}$ 3) y el derecho de propiedad (19 $\left.\mathrm{N}^{\circ} 24\right)$.

4. Respecto del recurso de protección, existe confusión en cuanto a los requisitos formales de admisión de éste, lo que obstaculiza y a veces impide la discusión central de la colisión entre derechos. Esto se ejemplifica en la falta de claridad en los supuestos de la legitimación activa y en la admisibilidad de la protección de ciertas garantías como el debido proceso.

5. Existe una clara corriente de limitación de la extensión del artículo $19 \mathrm{~N}^{\circ} 24$, el cual, en opinión de la Corte Suprema, no contendría el derecho de propiedad sobre el cargo o empleo.

6. En cuanto a las sentencias comentadas, una de las más relevantes y de mayor interés en la opinión pública fue la de la píldora del día después. El planteamiento de la Corte Suprema no se hace cargo del argumento del derecho de la autonomía de la mujer, y no pondera este derecho respecto del derecho a la vida. La ponderación parece el método más razonable de argumentación constitucional ante la colisión de derechos fundamentales, y en esta sentencia se omite tal razonamiento. En cuanto al voto de minoría que plantea que la vía de protección no es la más adecuada para resolver el problema, creemos que no es una postura del todo correcta ya que existe suficiente

\footnotetext{
${ }^{28}$ En este mismo número se publica el comentario que el profesor Navarrete ha hecho a este fallo, pp ... (n. de los editores).

${ }^{29}$ Rol 2218-00, 18 de abril de 2001, Libro Civil, № 5-7, recurso de casación forma y fondo, Lander de Tellitsu Sasía con Fisco.
} 
REJ - Revista de Estudios de la Justicia - No 3 - Año 2003

espacio para efectuar dicha argumentación constitucional.

7. Finalmente, se citan muchas veces decisiones judiciales del periodo de la Constitución de 1925 o del periodo pre-constitucional anterior a 1989 lo que resulta especialmente equivocado si pensamos que ya existe una abundante jurisprudencia constitucional chilena a partir del periodo constitucional democrático que se inicia en 1990. 